Ashraf, M., Gardner, L. and Nethercot, D.A. (2006). Compression strength of stainless steel cross-sections. Journal of Constructional Steel Research. 62(1-2), 105-115.

\title{
Compression strength of stainless steel cross-sections
}

\author{
Mahmud Ashraf ${ }^{1}$, Leroy Gardner ${ }^{2}$, David A. Nethercot ${ }^{3}$ \\ ${ }^{1}$ Ph.D. student (corresponding author) Department of Civil \& Environmental Engineering, Imperial College \\ London, SW7 2AZ, Tel: +44(0)2075946027, Fax: +44(0)2077252716, E-mail: mahmud.ashraf@imperial.ac.uk \\ ${ }^{2}$ Lecturer in Structural Engineering. , Dept. of Civil \& Env. Engg, Imperial College London. \\ ${ }^{3}$ Professor and Head, Dept. of Civil \& Env. Engg, Imperial College London
}

\begin{abstract}
A conceptually new approach which recognises the continuous nature of the stress-strain characteristic of stainless steel has recently been developed by the authors for the prediction of the strength of compressed plate elements in stainless steel members. This method does not use the classification system found in modern codes dealing with the structural design of carbon steel members. The original development was limited to plate elements supported on both longitudinal edges; the basic concept is expanded herein to cover a wider range of cases. The resulting design procedure forms part of a general treatment of stainless steel structural members that predicts resistances significantly in excess of those obtained from currently available design methods. These resistances are found to accord well with the observed strength of sections obtained in laboratory tests.
\end{abstract}

\section{KEYWORDS}

Cross-section slenderness, Cross-section strength, Deformation capacity, Enhanced corner strength, Open sections, Stainless steel.

\section{INTRODUCTION}

The physical characteristics of stainless steel - including high strength, stiffness and ductility, weldability, durability, ease of forming and machining, good fire resistance and readily re- 
usable and recyclable - makes the material ideally suited to use in construction. Recent years have seen significant advances towards effectively utilising these properties, such as the introduction or major revision of the principal structural stainless steel design standards worldwide, an enhanced range of products and wider product availability; all of this has been supported by heightened research activity. However, stainless steel is still viewed as an extravagant solution to structural engineering problems, and although the emergence of design codes is an important step forward, their inefficiency (due largely to overly-simplistic material modelling) is inhibiting more widespread use.

One of the principal drawbacks to these codes is that they were based on the rather limited amount of structural performance data available and a significant factor in their preparation was the initial need to ensure that a designer familiar with the carbon steel rules would be able to make a straightforward transition to stainless steel structural design. As a result, the authors were obliged to use a simplified elastic, perfectly-plastic material model. This model is acceptable for carbon steel that exhibits a sharply defined yield point, followed by a plastic yield plateau. For stainless steel, though, where there is no sharply defined yield point and substantial strain hardening is possible, this model leads to overly conservative designs.

It is clear that for a material with high initial cost, efficient design is paramount, and a more rigorous design approach that more accurately recognises and exploits the particular features of stainless steel can be justified. Gardner [1] initially focused on the austenitic family of stainless steels since these are the most widely used grades for structural applications throughout the world, though more recent work has since demonstrated extension of the method to other non-linear materials [2]. Test results for other grades of stainless steel have been incorporated in the present study to validate the method as a general design tool. 


\section{BACKGROUND}

\subsection{Laboratory testing}

A laboratory testing programme was carried out to investigate the behaviour of austenitic stainless steel cross-sections and members. Tests were conducted on square, rectangular and circular hollow sections (SHS, RHS and CHS respectively). Tensile and compressive coupon tests were carried out on flat material cut from the faces of finished SHS and RHS to determine the material stress-strain behaviour. Coupons cut from the corner regions of the cross-sections were also tested to investigate the effect of strain hardening. Stub column tests were conducted on SHS, RHS and CHS to enable the development of a relationship between cross-section slenderness $\beta$ and deformation capacity $\varepsilon_{\mathrm{LB}}$, and to determine ultimate load carrying capacities [3]. Member tests on SHS and RHS beams and columns were conducted to investigate structural behaviour and to determine ultimate load carrying capacities [4]. Initial geometric imperfections and residual stresses were measured to aid the explanation of structural performance and to use as basic data in numerical models.

The laboratory test results have led to an improved understanding of the structural behaviour of stainless steel and have been used as a means of validating numerical models. The results have also formed part of the validation of a proposed new design procedure.

\subsection{Numerical modelling}

Sophisticated numerical models have been developed using the finite element (FE) package ABAQUS. The models have included features such as measured (non-linear) material properties, measured geometry, rounded and enhanced strength corners, initial local and global geometric imperfections and residual stresses. Formulations have been also developed 
to provide general expressions for initial geometric imperfections, residual stresses and enhanced corner material properties, allowing a consistent approach to the generation of further results through parametric studies [5].

\subsection{Proposed design method for hollow sections}

\subsubsection{Concept}

The cross-section strength of stainless steel members is currently assessed on a similar basis to the cross-section strength of carbon steel members [6]. The cross-section is initially placed into one of a number of possible behavioural classes (with the number depending on the particular design code), and subsequently its strength is limited by either material yielding of the gross section, with either a plastic or elastic distribution of stresses, or yielding of an effective section (to account for local buckling) with an elastic stress distribution.

A new design approach has been proposed by Gardner [1], Gardner and Nethercot [7] and Gardner et al [8] that replaces these discrete behavioural classes with a continuous measure of the deformation capacity of the cross-section. The strength of the cross-section may then be determined using this deformation capacity in conjunction with a material model that accurately reflects the rounded nature of the stainless steel stress-strain curve.

\subsubsection{Development}

The deformation capacity $\varepsilon_{\mathrm{LB}}$ of a cross-section was defined as the deformation $\delta_{\mathrm{u}}$ corresponding to the peak of the load-end shortening curve, obtained from stub column tests (in pure compression) divided by the stub column length. All available stub column test results were used to develop a relationship between element slenderness $\beta$, defined by Eq. 1 
(based on the most slender element in the cross-section) and normalised element deformation capacity $\varepsilon_{\mathrm{LB}} / \varepsilon_{0}$, where $\varepsilon_{0}$ is the elastic strain at the material $0.2 \%$ proof stress. The results from tests on SHS were assumed to relate approximately to plate elements with simply-supported boundary conditions, since the four elements of the cross-section provide equal restraint to one another [9]. In the case of rectangular hollow sections, however, greater edge restraint is applied to the more slender sides of the cross-section by the less slender sides. As a result, higher buckling curves can be applied to the more slender sides of rectangular hollow sections, and clearly an increase in aspect ratio produces an increase in edge restraint. A modification factor involving the aspect ratio was incorporated into the basic relationship obtained for the SHS to arrive at a general expression for the hollow sections [1].

The local buckling strain of a cross-section was, thus, obtained from the proposed equations, and the compound Ramberg-Osgood model [1], developed on the basis of a similar expression proposed by Mirambell and Real [10], was used to obtain the corresponding local buckling stress $\sigma_{\mathrm{LB}}$. Compression resistance is thus defined as the product of the local buckling strength $\sigma_{\mathrm{LB}}$ and the gross area of the cross-section $\mathrm{Ag}$.

\subsubsection{Validation}

Results from the proposed method have been compared against all available test results on austenitic stainless steel hollow sections $[1,8]$. The comparison showed that the proposed method gives excellent prediction of the test results, and offers a considerable benefit over the Eurocode approach. For SHS and RHS compression resistance, the Eurocode design method predicts, on average, $78 \%$ of the test failure load with a standard deviation of $13 \%$, whereas the proposed design method predicts $95 \%$ of the test failure load with a standard deviation of $8 \%$ resulting in a $25 \%$ increase in cross-sectional resistance. 


\section{EXTENSION OF PROPOSED METHOD}

\subsection{Test results used for open sections}

The success of the proposed method for hollow sections opens the way for its extension to cover all types of sections. All available test results on stainless steel open sections as reported by Kuwamura [11], Stangenberg [12], Lecce and Rasmussen [13] have been analysed with a view to obtaining a generalised method for all stainless steel sections comprising flat plate elements. A similar treatment for circular sections is described elsewhere $[1,7]$.

Kuwamura [11] investigated the local buckling behaviour of thin-walled stainless steel sections through an extensive testing scheme. A total of 63 stub columns from Grades 1.4301 and 1.4318 with angle, channel, lipped channel, $\mathrm{H}$ and square hollow cross-sections were tested. All the sections were cold-formed by press-braking at the corners apart from the welded H sections. Stangenberg [12] reported stub column tests on welded H sections, conducted as a part of the ECSC funded project 'Development of use of stainless steel in construction'. Three specimens were made from Grade 1.4301 while the other one was from Grade 1.4462. Lecce and Rasmussen [13] tested lipped channel stub columns produced from Grades $1.4301,1.4016$ and 1.4003 to study the distortional buckling behaviour of coldformed stainless steel sections. Table 1 gives a summary of the stub columns with outstands used in the present study.

The slenderness parameter $\beta$ is defined by Eq. 1, and has been determined on the basis of the most slender element in the cross-section. 


$$
\beta=\frac{b}{t} \sqrt{\frac{\sigma_{0.2}}{E_{0}}} \sqrt{\frac{4}{k}}
$$

where

$\sigma_{0.2}$ is the material $0.2 \%$ proof stress in compression

$\mathrm{E}_{0}$ is the material Young's modulus

$\mathrm{b}$ is the flat face width measured between centrelines (except for the welded I sections) of adjacent faces as shown in Fig. 1

$t$ is the wall thickness of the cross-section

$\mathrm{k}$ is the buckling coefficient whose value for internal and outstand elements in the case of pure compression is taken as 4.0 and 0.43 respectively [14].

\subsection{Design curve for local buckling strain $\varepsilon_{\mathrm{LB}}$}

Following the same concept as for the hollow sections [8], a generalised relationship was established for all the cross-sections containing flat plate elements. The relationship between the cross-section slenderness $\beta$ and normalised local buckling strain $\varepsilon_{\mathrm{LB}} / \varepsilon_{0}$ is shown in Fig. 2 .

From Fig. 2 it is observed that all cross sections follow a common trend when the slenderness $\beta$ of the most slender element of a cross-section is calculated using the appropriate buckling coefficient $\mathrm{k}$. For outstand elements in pure compression the buckling coefficient is taken as 0.43, whereas for all internal compression elements its value is taken as 4.0. Initial studies [1] have also indicated that the theoretical buckling coefficients ks given in Tables 5.3.2 and 5.3.3 of ENV 1993-1-1 [14] may be adopted in Eq. 1 to account for other linearly varying stress distributions (eg. pure bending). All the test results were simulated using sophisticated FE models that include effects of corner enhancement, predicted initial imperfections following established guidelines and thermal residual stresses in the case of welded $\mathrm{H}$ 
sections. The predictions of the developed numerical models were in good agreement with the test results [15]; some additional results were generated using the validated FE technique for cases where test results were scarce as seen in Fig. 2. The generated points also follow the same path as shown in Fig. 3. A regression analysis was performed to obtain the generalised relationship between the cross-section deformation capacity and cross-section slenderness which is given by Eq. 2. Fig. 3 compares Eq. 2 to all the stub column results.

$$
\text { For all sections, } \quad \frac{\varepsilon_{\mathrm{LB}}}{\varepsilon_{0}}=\frac{7.547}{\beta^{2.527-0.221 \beta}}
$$

\subsection{Local buckling stress $\sigma_{\text {LB }}$ using the material stress-strain behaviour}

The local buckling strain $\varepsilon_{\mathrm{LB}}$ of a cross-section can be determined from Eq. 2 and this strain can be used to obtain the local buckling stress $\sigma_{\mathrm{LB}}$ from the material stress-strain relationship. For practical cases it is preferable to establish a stress-strain relationship such that the stress can be directly obtained from the strain. The compound Ramberg-Osgood model, as expressed in Eqs 3 and 4, can be used to model the stainless steel behaviour very accurately, but relates strain as a function of stress. Since stress cannot be obtained directly from this model, the material behaviour can be presented in a tabular form to enable designers to obtain $\sigma_{\mathrm{LB}}$ directly from $\varepsilon_{\mathrm{LB}}$ without the need for iteration.

$$
\begin{array}{ll}
\varepsilon=\frac{\sigma}{\mathrm{E}_{0}}+0.002\left(\frac{\sigma}{\sigma_{0.2}}\right)^{\mathrm{n}} & \left(\sigma \leq \sigma_{0.2)}\right) \\
\varepsilon=\frac{\left(\sigma-\sigma_{0.2}\right)}{\mathrm{E}_{0.2}}+\left(0.008-\frac{\sigma_{1.0}-\sigma_{0.2}}{\mathrm{E}_{0.2}}\right)\left(\frac{\sigma-\sigma_{0.2}}{\sigma_{1.0}-\sigma_{0.2}}\right)^{\mathrm{n}_{0.2,1.0}^{\prime}}+\varepsilon_{\mathrm{t} 0.2} & \left(\sigma \geq \sigma_{0.2}\right)
\end{array}
$$

where

$\sigma_{0.2}$ and $\sigma_{1.0}$ are $0.2 \%$ and $1 \%$ proof stress respectively

$\varepsilon_{t, 0.2}$ is the total strain at the $0.2 \%$ proof stress 
$\mathrm{n}$ and $\mathrm{n}^{\prime}{ }_{0.2,1.0}$ are strain hardening coefficients

$\mathrm{E}_{0}$ is the initial Young's Modulus

$\mathrm{E}_{0.2}$ is the stiffness at $0.2 \%$ proof stress.

From a structural point of view, it is an essential requirement to know the basic stress-strain behaviour of a material prior to using it in practice. Standard coupons are tested to produce this basic stress-strain behaviour. In the case of stainless steel, numerous coupon tests have been reported by Rasmussen and Hancock [16], Talja and Salmi [17], Macdonald et al [18], Mirambell and Real [10], Stangenberg [12]; Gardner [1], Young and Liu [19]. Most of these involved austenitic Grade 1.4301 since this is the most widely used type of stainless steel. Coupons were cut from both cold-formed and press-braked sections. The test results are summarised in Table 2 stating the average values for Young's modulus $E_{0}, \sigma_{1.0} / \sigma_{0.2}$ and the compound Ramberg-Osgood parameters $\mathrm{n}$ and $\mathrm{n}_{0.2,1.0}$.

These tabulated values are used to develop Tables 3, 4 and 5 following Eqs. 3 and 4, which will be used to obtain the local buckling stress $\sigma_{\mathrm{LB}}$ by knowing $\varepsilon_{\mathrm{LB}}$ from Eq. 2 and $\sigma_{0.2}$.

\subsection{Validation of the proposed technique}

The proposed technique for the determination of compressive strength involves the following parameters:

i. Cross-section slenderness $\beta$ for the most slender element using Eq. 1

ii. Local buckling strain $\varepsilon_{\text {Lв }}$ using Eq. 2

iii. Local buckling stress $\sigma_{\mathrm{LB}}$ from the appropriate table (Table 3, 4 or 5)

iv. Compressive strength $\mathrm{N}_{\mathrm{c}, \mathrm{Rd}}\left(\right.$ or $\mathrm{F}_{\mathrm{u}}$ ) is equal to $\sigma_{\mathrm{LB}}$ times the gross area $\mathrm{Ag}_{\mathrm{g}}$ 
The compressive strengths of all the stub columns have been determined following these steps and the results are compared to the test results in Fig. 4.

From Fig. 4 it is observed that the predictions are somewhat scattered, the standard deviation being 0.21 with a mean of 1.07 . For the relatively stocky sections with $\beta \leq 1.5$, most of the predictions are less than the test results, whereas for slender specimens the predicted strengths are rather high when compared to the test results. This comparison clearly suggests that some modifications are required to make predictions closer to the test results.

\section{ANALYSIS OF RESULTS AND PROPOSED MODIFICATIONS}

The proposed approach directly uses the material stress-strain behaviour to obtain the local buckling stress for the stub columns. In reality, stub column stress-strain curves differ from material coupon stress-strain curves due to the presence of residual stresses and enhanced strength at the corners. Thermal residual stresses, in the case of hollow and $\mathrm{H}$ sections, have been shown to have little influence on stub column behaviour [1 \& 15] and the bending residual stresses are re-introduced into the coupons in the process of testing. Enhanced corner strength, on the other hand, plays a very significant role in the case of relatively stocky sections and the use of only the basic material stress-strain curve underestimates the compressive strength. As the section becomes more slender, the corner region loses its significance, gradually, and the local plate buckling at stresses below $\sigma_{0.2}$ dominates failure. Post buckling behaviour has also been found to be significant in the case of slender columns, causing the stub column stress-strain behaviour to deviate from that of the coupon before reaching the peak stress [1]. This causes some overestimation in compressive strength for the relatively slender cross-sections with $\beta>1.5$. These features are illustrated in Fig. 5 . 


\subsection{Correction for sections with enhanced corner strength}

Stainless steel exhibits pronounced strain hardening, resulting in the corner regions of coldformed sections having $0.2 \%$ proof strengths much higher than that of the flat material. Failure to allow for these enhanced strength regions in design leads to under-predictions of load carrying capacity. This effect has been found to be very important in the case of stocky sections since they normally contain a larger proportion of corner area. A correction factor is, therefore, required to explicitly include the effects of corner enhancements and to bring the predictions closer to the test results.

Ashraf et al [20] proposed models to predict the $0.2 \%$ proof strength and ultimate strength of corner regions after a comprehensive investigation of the available test results. Separate models were proposed to allow for the difference between the roll-forming and press-braking processes. Two different correction factors are proposed herein for the prediction of crosssection strength of the roll-formed and press-braked specimens.

\subsubsection{Correction for roll-formed sections}

The material properties of the flat region of roll-formed sections are different from those of the virgin material because of the cold-work done in the roll-forming process. The following expressions hold true for a roll-formed section,

$$
\begin{aligned}
\mathrm{F}_{\mathrm{u}} & =\mathrm{A}_{\mathrm{f} .} \sigma_{0.2, \mathrm{f}}+\mathrm{A}_{\mathrm{c}} \cdot \sigma_{0.2, \mathrm{c}} \\
& =\mathrm{Ag}_{\mathrm{g}}\left[\mathrm{A}_{\mathrm{f}} / \mathrm{A}_{\mathrm{g}} \cdot \sigma_{0.2, \mathrm{f}}+\mathrm{A}_{\mathrm{c}} / \mathrm{Ag}_{\mathrm{g}} \cdot \sigma_{0.2, \mathrm{c}}\right] \\
& =\mathrm{Ag}_{\mathrm{g}}\left[\left(1-\mathrm{k}_{\mathrm{cor}}\right) \cdot \sigma_{0.2, \mathrm{f}}+\mathrm{k}_{\mathrm{cor}}\left(0.82 \sigma_{\mathrm{u}, \mathrm{f}}\right)\right] \\
& =\mathrm{Ag}_{\mathrm{g}}\left[\left(1-\mathrm{k}_{\mathrm{cor}}\right) \cdot \sigma_{0.2, \mathrm{f}}+\mathrm{k}_{\mathrm{cor}}\left(0.82 \times 1.61 \sigma_{0.2, \mathrm{f}}\right)\right] \\
& =A_{g} \cdot \sigma_{0.2, \mathrm{f}}\left(1+0.32 \mathrm{k}_{\mathrm{cor}}\right)
\end{aligned}
$$


where,

$$
\begin{aligned}
& \mathrm{F}_{\mathrm{u}}=\text { peak load of the stub column } \\
& A_{\mathrm{f}}=\text { area of the flat region } \\
& \mathrm{A}_{\mathrm{c}}=\text { area of the corner region } \\
& \mathrm{A}_{\mathrm{g}}=\text { gross area, } \mathrm{A}_{\mathrm{f}}+\mathrm{A}_{\mathrm{c}} \\
& \mathrm{k}_{\mathrm{cor}}=\text { proportion of corner region, } \mathrm{Ac}_{\mathrm{c}} / \mathrm{Ag}_{\mathrm{g}} \\
& \sigma_{0.2, \mathrm{f}}=0.2 \% \text { proof stress of the flat material } \\
& \sigma_{0.2, \mathrm{c}}=0.2 \% \text { proof stress of the corner material }\left(=0.82 \sigma_{\mathrm{u}, \mathrm{f}}\right)[20] \\
& \sigma_{0 \mathrm{u}, \mathrm{f}}=\mathrm{ultimate} \text { strength of the flat material }\left(=1.61 \sigma_{0.2, \mathrm{f}}\right)[1]
\end{aligned}
$$

Thus the cross-section strength of a roll-formed section should be multiplied by the factor (1 $+0.32 \mathrm{k}_{\text {cor }}$ ) to account for the material strength enhancements in the corner (and flat) regions.

\subsubsection{Correction for press-braked sections}

In the case of press-braked sections, the material properties of the flat region can be taken to be the same as the virgin material, increases in the $0.2 \%$ proof strength only at the corners. The strength of a press-braked section can be expressed as follows,

$$
\begin{aligned}
\mathrm{F}_{\mathrm{u}} & =\mathrm{A}_{\mathrm{f} .} \sigma_{0.2, \mathrm{v}}+\mathrm{Ac}_{\mathrm{c} .} \sigma_{0.2, \mathrm{c}} \\
& =\operatorname{Ag}\left[\mathrm{Af} / \mathrm{Ag}_{\mathrm{g} .} \sigma_{0.2, \mathrm{v}}+\mathrm{A}_{\mathrm{c}} / \mathrm{Ag}_{\mathrm{g} .} \sigma_{0.2, \mathrm{c}}\right] \\
& =\operatorname{Ag}\left[\left(1-\mathrm{k}_{\mathrm{cor}}\right) \cdot \sigma_{0.2, \mathrm{v}}+\mathrm{k}_{\mathrm{cor}} 1.881 /\left(\frac{\mathrm{r}_{\mathrm{i}}}{\mathrm{t}}\right)^{0.194} \cdot \sigma_{0.2, \mathrm{v}}\right] \\
& =A_{g} \cdot \sigma_{0.2, \mathrm{v}}\left[1+\left\{1.881 /\left(\frac{\mathrm{r}_{\mathrm{i}}}{\mathrm{t}}\right)^{0.194}-1\right\} \mathrm{k}_{\mathrm{cor}}\right]
\end{aligned}
$$

where,

$$
\sigma_{0.2, \mathrm{v}}=0.2 \% \text { proof stress of the flat (virgin) material }
$$




$$
\sigma_{0.2, \mathrm{c}}=0.2 \% \text { proof stress of the corner material }\left[=1.881 /\left(\frac{\mathrm{r}_{\mathrm{i}}}{\mathrm{t}}\right)^{0.194} \cdot \sigma_{0.2, \mathrm{v}}\right][20]
$$

Thus the cross-section strength of a press-braked section should be multiplied by the factor $\left[1+\left\{1.881 /\left(\frac{\mathrm{r}_{\mathrm{i}}}{\mathrm{t}}\right)^{0.194}-1\right\} \mathrm{k}\right.$ cor $]$, to account for the localised corner strength enhancements.

\subsection{Correction for slender sections with $\beta>1.5$}

A simple linear regression analysis was performed to obtain a reduction factor for the slender sections. The local buckling stress obtained from the material stress-strain table should be multiplied by the factor $(-0.154 \beta+1.186)$ to obtain the appropriate value.

It should be noted that for a slender cross-section with corner regions, the local buckling stress obtained from the table should be multiplied by two factors - enhancement for corner regions followed by a reduction for its slenderness.

\section{DETAILED COMPARISONS}

Strengths of all the stub columns have been predicted using the proposed method with appropriate corrections and the detailed results are given in Table 6. A summary of the predictions is given in Table 7.

From Table 7 it is observed that the proposed corrections make the predictions closer to the test results - average prediction and standard deviation for all sections become 1.00 and 0.12 , in place of 1.07 and 0.21 , respectively. Figure 11 shows a comparison of the predictions to the test results after using the corrections. The reduction in scatter is clear if Fig.6 is compared with Fig. 4. 
However some predictions for SHS stub columns formed by welding two press-braked channel sections tip-to-tip (Kuwamura, Grade 1.4318 [11]) are surprisingly high and inconsistent with the other predictions. The FE models for these stub columns provide some answers to this contradiction. The ultimate loads reported for these columns are significantly smaller than the FE results. Table 8 lists the FE results and compares the predicted strength to the test and FE results. Both the average and scatter shows a significant improvement if the proposed predictions are compared to the FE results rather than the reported test results. It is worth mentioning that apart from these stub columns all the numerical predictions are in good agreement with the test results [15].

\section{CONCLUSIONS}

This paper has explained how test and numerical results for stainless steel sections have been used to develop and calibrate a new design method for stainless steel structures which uses a common technique to determine the compressive strength for all types of cross-sections without the need for traditional section classification. This new method offers material savings of around $25 \%$ for hollow sections over current design methods, whilst retaining safe-side predictions, and for a similar volume of calculation. Further work is underway to extend this method for all types of loading and expedite its introduction into common use as a practical design tool.

\section{ACKNOWLEDGMENTS}

The authors would like to thank EPSRC, the AvestaPolarit UK Research Foundation and the Commonwealth Scholarship Commission for funding the described work. 


\section{REFERENCES}

[1] Gardner, L. (2002), A new approach to structural stainless steel design, Ph.D. Thesis, Department of Civil and Environmental Engineering, Imperial College London.

[2] Gardner, L. (2005), Structural design for non-linear metallic materials, Accepted for publication in the proceedings of the Fourth European Conference on Steel and Composite Structures - Eurosteel. 8th-10th June 2005. Maastricht, The Netherlands.

[3] Gardner, L. and Nethercot D.A. (2004), Experiments on stainless steel hollow sections Part 1: Material and cross-sectional behaviour, Journal of Constructional Steel Research, Vol. 60, pp. 1291-1318.

[4] Gardner, L. and Nethercot D.A. (2004), Experiments on stainless steel hollow sections Part 2: Member behaviour of columns and beams, Journal of Constructional Steel Research, Vol. 60, pp. 1319-1332.

[5] Gardner, L. and Nethercot, D. A. (2004), Numerical modelling of stainless steel structural components - A consistent approach, Journal of Structural Engineering, ASCE, Vol. 130, No. 10, pp. 1586-1601.

[6] ENV 1993-1-4 (1996), Eurocode 3: Design of steel structures - Part 1.4: General rules Supplementary rules for stainless steel, CEN.

[7] Gardner, L. and Nethercot, D. A. (2004). Stainless steel structural design: A new approach, The Structural Engineer, Vol. 82, No. 21, pp. 21-28.

[8] Gardner, L., Ashraf, M. and Nethercot, D. A. (2004), Cross-section strength of stainless steel members, Proceedings of the Progress in Structural Engineering, Mechanics and Computation, Cape Town, South Africa, pp.1417-1421.

[9] Timoshenko, S. P. and Gere, J. M. (1985), Theory of elastic stability, McGraw-Hill International Book Company, New York. 
[10] Mirambell, E. and Real, E. (2000), On the calculation of deflections in structural stainless steel beams: an experimental and numerical investigation, Journal of Constructional Steel Research, Vol. 54, pp.109-133.

[11] Kuwamura, H. (2003), Local buckling of thin-walled stainless steel members, Steel Structures, Vol. 3, pp. $191-201$.

[12] Stangenberg, H (2000), Development of the use of stainless steel in construction, Work Package - 2, ECSC funded project, Contract no. 7210 SA/134, RWTH.

[13] Lecce, M. and Rasmussen, K. (2004), Experimental investigations of distortional buckling of cold-formed stainless steel sections, Proceedings of the $17^{\text {th }}$ International Specialty Conference on Cold-formed Steel Structures, Orlando, USA.

[14] ENV 1993-1-1. (1992), Design of steel structures - Part 1.1: General rules and rules for buildings, CEN.

[15] Ashraf, M, Gardner, L. and Nethercot, D. A (2005)., Numerical modelling of stainless steel open sections, Accepted for publication in the proceedings of the Fourth European Conference on Steel and Composite Structures - Eurosteel. 8th-10th June 2005. Maastricht, The Netherlands.

[16] Rasmussen, K. J. R. and Hancock, G. J. (1990), Stainless steel tubular columns - tests and design, Proceedings of the Tenth International Specialty Conference on Coldformed Steel Structures, St. Louis, Missouri, U.S.A.

[17] Talja, A. \& Salmi, P. (1995), Design of stainless steel RHS beams, columns and beamcolumns, Research Note 1619, VTT Building Technology, Finland.

[18] Macdonald, M., Rhodes, J. and Taylor, G.T. (2000), Mechanical properties of stainless steel lipped channels, Proceedings of the $15^{\text {th }}$ International Specialty Conference on Cold-formed Steel Structures, University of Missouri-Rolla, pp. 673-686. 
[19] Young, B. and Liu, Y. (2003), Experimental investigation of cold-formed stainless steel columns, Journal of Structural Engineering, ASCE, Vol. 129, No. 2, pp. 169 - 176.

[20] Ashraf, M., Gardner, L. and Nethercot, D. A. (2005), Strength enhancement of the corner regions of stainless steel cross-sections, Journal of Constructional and Steel Research, Vol. 61, No. 1, pp. 37-52. 
Table 1 Test results used in the present study.

\begin{tabular}{cc|ccc}
\hline Reference & Grades & Cross-section & No. of stub columns & $\beta$ \\
\hline \multirow{3}{*}[11]{} & \multirow{3}{*}{$1.4301,1.4318$} & Angle & 12 & $0.89-3.17$ \\
& & Channel & 11 & $0.91-2.67$ \\
& & Lipped channel & 12 & $1.24-3.58$ \\
& & H-section & 16 & $0.93-3.99$ \\
& & SHS & 12 & $0.61-3.58$ \\
\hline$[12]$ & $1.4301,1.4462$ & H- section & 4 & $0.90-1.94$ \\
\hline$[13]$ & 1.4301, & Lipped channel & 10 & $1.81-2.21$ \\
\hline
\end{tabular}

Table 2 Summary of the coupon test results.

\begin{tabular}{c|ccccc}
\hline Type & Grade & $\begin{array}{c}\mathrm{E}_{0} \\
\left(\mathrm{~N} / \mathrm{mm}^{2}\right)\end{array}$ & $\mathrm{n}$ & $\mathrm{n}_{0.2,1.0}^{\prime}$ & $\sigma_{1.0} / \sigma_{0.2}$ \\
\hline \multirow{2}{*}{ Press-braked } & 1.4301 & 194000 & 8.5 & 1.66 & 1.13 \\
& 1.4318 & 187000 & 9.6 & 2.7 & 1.08 \\
\hline Roll-formed & 1.4301 & 201000 & 4.3 & 2.7 & 1.26 \\
\hline
\end{tabular}

Table 3 Local buckling stress $\sigma_{\text {Lв }}\left(\mathrm{N} / \mathrm{mm}^{2}\right)$ for press-braked sections of Grade 1.4301

\begin{tabular}{|c|c|c|c|c|c|c|c|c|c|}
\hline \multirow{2}{*}{$\varepsilon_{\mathrm{LB}}$} & \multicolumn{9}{|c|}{$\sigma_{0.2}\left(\mathrm{~N} / \mathrm{mm}^{2}\right)$} \\
\hline & 240 & 260 & 280 & 300 & 340 & 380 & 420 & 460 & 500 \\
\hline 0.001 & 172 & 178 & 184 & 187 & 191 & 192 & 194 & 194 & 194 \\
\hline 0.002 & 218 & 233 & 248 & 263 & 289 & 313 & 333 & 350 & 363 \\
\hline 0.003 & 237 & 255 & 273 & 290 & 324 & 356 & 388 & 416 & 443 \\
\hline 0.004 & 246 & 265 & 285 & 305 & 343 & 381 & 416 & 451 & 485 \\
\hline 0.005 & 251 & 271 & 291 & 312 & 352 & 391 & 431 & 469 & 507 \\
\hline 0.006 & 255 & 276 & 296 & 317 & 358 & 399 & 439 & 479 & 519 \\
\hline 0.007 & 258 & 280 & 301 & 322 & 364 & 405 & 446 & 487 & 528 \\
\hline 0.008 & 262 & 283 & 305 & 326 & 368 & 411 & 453 & 494 & 536 \\
\hline 0.009 & 265 & 287 & 308 & 330 & 373 & 416 & 458 & 501 & 543 \\
\hline 0.010 & 268 & 290 & 312 & 334 & 377 & 421 & 464 & 507 & 550 \\
\hline 0.012 & 273 & 296 & 318 & 341 & 385 & 430 & 474 & 518 & 562 \\
\hline 0.014 & 278 & 301 & 324 & 347 & 392 & 438 & 483 & 528 & 573 \\
\hline 0.016 & 283 & 306 & 329 & 353 & 399 & 445 & 491 & 537 & 583 \\
\hline 0.018 & 287 & 311 & 335 & 358 & 405 & 452 & 499 & 546 & 593 \\
\hline 0.020 & 292 & 315 & 339 & 363 & 411 & 459 & 507 & 554 & 602 \\
\hline 0.024 & 299 & 324 & 349 & 373 & 423 & 472 & 521 & 570 & 619 \\
\hline 0.028 & 307 & 332 & 357 & 382 & 433 & 483 & 534 & 584 & 634 \\
\hline 0.032 & 313 & 339 & 365 & 391 & 443 & 494 & 546 & 597 & 649 \\
\hline 0.036 & 320 & 346 & 373 & 399 & 452 & 505 & 558 & 610 & 663 \\
\hline 0.040 & 326 & 353 & 380 & 407 & 461 & 515 & 569 & 622 & 676 \\
\hline 0.050 & 340 & 369 & 397 & 425 & 482 & 538 & 594 & 651 & 707 \\
\hline 0.060 & 354 & 383 & 412 & 442 & 501 & 560 & 618 & 677 & 736 \\
\hline 0.070 & 366 & 397 & 427 & 457 & 518 & 579 & 640 & 701 & 762 \\
\hline 0.080 & 378 & 409 & 441 & 472 & 535 & 598 & 661 & 724 & 787 \\
\hline 0.090 & 389 & 422 & 454 & 486 & 551 & 616 & 681 & 746 & 811 \\
\hline 0.100 & 400 & 433 & 466 & 500 & 566 & 633 & 700 & 767 & 833 \\
\hline
\end{tabular}


Table 4 Local buckling stress $\sigma_{\mathrm{LB}}\left(\mathrm{N} / \mathrm{mm}^{2}\right)$ for press-braked sections of Grade 1.4318

\begin{tabular}{|c|c|c|c|c|c|c|c|c|c|}
\hline \multirow{2}{*}{$\varepsilon_{\mathrm{LB}}$} & \multicolumn{9}{|c|}{$\sigma_{0.2}\left(\mathrm{~N} / \mathrm{mm}^{2}\right)$} \\
\hline & 350 & 400 & 440 & 480 & 520 & 560 & 600 & 650 & 700 \\
\hline 0.001 & 187 & 187 & 187 & 187 & 187 & 187 & 187 & 187 & 187 \\
\hline 0.002 & 297 & 324 & 341 & 354 & 363 & 367 & 370 & 372 & 373 \\
\hline 0.003 & 333 & 372 & 402 & 430 & 456 & 478 & 498 & 518 & 533 \\
\hline 0.004 & 352 & 397 & 432 & 466 & 499 & 530 & 559 & 593 & 624 \\
\hline 0.005 & 361 & 410 & 450 & 488 & 525 & 561 & 594 & 635 & 674 \\
\hline 0.006 & 365 & 416 & 457 & 497 & 537 & 576 & 615 & 662 & 707 \\
\hline 0.007 & 368 & 420 & 461 & 502 & 543 & 583 & 624 & 673 & 723 \\
\hline 0.008 & 371 & 423 & 465 & 506 & 548 & 589 & 630 & 681 & 731 \\
\hline 0.009 & 373 & 426 & 468 & 510 & 551 & 593 & 634 & 686 & 737 \\
\hline 0.010 & 375 & 428 & 470 & 513 & 554 & 596 & 638 & 691 & 742 \\
\hline 0.012 & 378 & 432 & 474 & 517 & 560 & 602 & 645 & 698 & 750 \\
\hline 0.014 & 381 & 435 & 478 & 521 & 564 & 607 & 650 & 704 & 757 \\
\hline 0.016 & 383 & 438 & 481 & 525 & 568 & 611 & 655 & 709 & 762 \\
\hline 0.018 & 385 & 440 & 484 & 528 & 571 & 615 & 659 & 713 & 467 \\
\hline 0.020 & 387 & 442 & 487 & 531 & 575 & 618 & 662 & 717 & 772 \\
\hline 0.024 & 391 & 447 & 491 & 536 & 580 & 624 & 669 & 724 & 779 \\
\hline 0.028 & 394 & 450 & 495 & 540 & 585 & 629 & 674 & 730 & 786 \\
\hline 0.032 & 397 & 453 & 499 & 544 & 589 & 634 & 679 & 736 & 792 \\
\hline 0.036 & 399 & 456 & 502 & 547 & 593 & 638 & 683 & 740 & 797 \\
\hline 0.040 & 402 & 459 & 505 & 551 & 596 & 640 & 688 & 745 & 802 \\
\hline 0.050 & 407 & 465 & 511 & 558 & 604 & 650 & 697 & 755 & 813 \\
\hline 0.060 & 411 & 470 & 517 & 564 & 611 & 658 & 705 & 764 & 822 \\
\hline 0.070 & 415 & 475 & 522 & 569 & 617 & 664 & 712 & 771 & 830 \\
\hline 0.080 & 419 & 479 & 527 & 574 & 622 & 670 & 718 & 778 & 838 \\
\hline 0.090 & 422 & 483 & 531 & 579 & 627 & 676 & 724 & 784 & 845 \\
\hline 0.100 & 426 & 486 & 535 & 583 & 632 & 681 & 730 & 790 & 851 \\
\hline
\end{tabular}

Table 5 Local buckling stress $\sigma_{\text {LB }}\left(\mathrm{N} / \mathrm{mm}^{2}\right)$ for roll-formed sections of Grade 1.4301

\begin{tabular}{|c|c|c|c|c|c|c|c|c|c|}
\hline \multirow{2}{*}{$\varepsilon_{\mathrm{LB}}$} & \multicolumn{9}{|c|}{$\sigma_{0.2}\left(\mathrm{~N} / \mathrm{mm}^{2}\right)$} \\
\hline & 200 & 240 & 280 & 320 & 360 & 400 & 440 & 480 & 520 \\
\hline 0.001 & 131 & 148 & 161 & 171 & 179 & 184 & 188 & 192 & $\overline{196}$ \\
\hline 0.002 & 174 & 203 & 229 & 252 & 274 & 292 & 309 & 324 & 340 \\
\hline 0.003 & 200 & 235 & 268 & 299 & 328 & 356 & 381 & 405 & 431 \\
\hline 0.004 & 216 & 256 & 295 & 332 & 367 & 400 & 431 & 461 & 493 \\
\hline 0.005 & 225 & 268 & 310 & 351 & 391 & 430 & 468 & 504 & 543 \\
\hline 0.006 & 232 & 276 & 320 & 364 & 407 & 448 & 489 & 530 & 574 \\
\hline 0.007 & 237 & 283 & 328 & 373 & 418 & 461 & 505 & 547 & 592 \\
\hline 0.008 & 241 & 288 & 335 & 381 & 426 & 472 & 516 & 560 & 608 \\
\hline 0.009 & 245 & 293 & 340 & 387 & 434 & 480 & 526 & 572 & 622 \\
\hline 0.010 & 248 & 297 & 345 & 393 & 441 & 488 & 535 & 581 & 631 \\
\hline 0.012 & 254 & 304 & 354 & 403 & 452 & 501 & 549 & 598 & 651 \\
\hline 0.014 & 259 & 310 & 361 & 412 & 461 & 511 & 561 & 611 & 665 \\
\hline 0.016 & 263 & 316 & 367 & 419 & 470 & 521 & 572 & 622 & 676 \\
\hline 0.018 & 268 & 320 & 373 & 426 & 478 & 529 & 581 & 632 & 687 \\
\hline 0.020 & 271 & 325 & 378 & 431 & 484 & 537 & 590 & 642 & 699 \\
\hline 0.024 & 277 & 333 & 388 & 442 & 497 & 551 & 605 & 658 & 716 \\
\hline 0.028 & 284 & 340 & 396 & 451 & 508 & 563 & 618 & 673 & 733 \\
\hline 0.032 & 289 & 346 & 403 & 461 & 517 & 574 & 630 & 687 & 749 \\
\hline 0.036 & 294 & 352 & 410 & 468 & 526 & 584 & 641 & 698 & 760 \\
\hline 0.040 & 298 & 357 & 416 & 476 & 534 & 592 & 652 & 710 & 773 \\
\hline 0.050 & 308 & 369 & 430 & 491 & 552 & 613 & 673 & 735 & 803 \\
\hline 0.060 & 316 & 379 & 442 & 505 & 568 & 630 & 693 & 755 & 823 \\
\hline 0.080 & 331 & 397 & 463 & 529 & 594 & 660 & 725 & 791 & 863 \\
\hline 0.100 & 344 & 412 & 480 & 548 & 616 & 685 & 752 & 821 & 896 \\
\hline
\end{tabular}


Table 6 Comparison of predicted results with tests.

\begin{tabular}{|c|c|c|c|c|c|c|c|c|c|c|}
\hline Ref. & $\begin{array}{l}\text { Type, } \\
\text { Grade }\end{array}$ & Nom. size & $\beta$ & $\varepsilon_{\mathrm{LB}}$ & $\begin{array}{c}\sigma_{\mathrm{LB}} \\
\mathrm{N} / \mathrm{mm}^{2}\end{array}$ & $\begin{array}{l}\text { Cor. } \\
\text { factor }\end{array}$ & $\begin{array}{c}\text { A } \\
\mathrm{mm}^{2} \\
\end{array}$ & $\begin{array}{c}\text { Pred } \mathrm{F}_{\mathrm{u}} \\
\mathrm{kN}\end{array}$ & $\begin{array}{c}\text { Test } \mathrm{F}_{\mathrm{u}} \\
\mathrm{kN}\end{array}$ & $\begin{array}{l}\text { Pred } F_{u} \\
/ \text { Test } F_{u}\end{array}$ \\
\hline \multirow{12}{*}{ 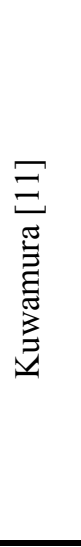 } & \multirow{6}{*}{$\begin{array}{c}\mathrm{L} \\
1.4301\end{array}$} & $25 \times 25 \times 3$ & 0.89 & 0.0131 & 301.1 & 1.13 & 130 & 44.1 & 55.9 & 0.79 \\
\hline & & $30 \times 30 \times 3$ & 1.08 & 0.0084 & 286.8 & 1.11 & 158 & 50.5 & 59.4 & 0.85 \\
\hline & & $40 \times 40 \times 3$ & 1.45 & 0.0043 & 268.8 & 1.08 & 217 & 63.3 & 66.9 & 0.95 \\
\hline & & $40 \times 40 \times 3$ & 1.45 & 0.0044 & 269.4 & 1.09 & 217 & 63.6 & 65.6 & 0.97 \\
\hline & & $50 \times 50 \times 3$ & 1.83 & 0.0027 & 250.1 & 0.96 & 276 & 66.5 & 68.7 & 0.97 \\
\hline & & $60 \times 60 \times 3$ & 2.17 & 0.0020 & 234.5 & 0.90 & 335 & 70.4 & 69.6 & 1.01 \\
\hline & \multirow{6}{*}{$\begin{array}{c}\mathrm{L} \\
1.4318\end{array}$} & $25 \times 25 \times 3$ & 1.32 & 0.0118 & 582.5 & 1.13 & 135 & 89.3 & 79.7 & 1.12 \\
\hline & & $30 \times 30 \times 3$ & 1.58 & 0.0081 & 570.5 & 1.06 & 162 & 97.7 & 89.8 & 1.09 \\
\hline & & $40 \times 40 \times 3$ & 2.09 & 0.0048 & 539.0 & 0.93 & 225 & 113.2 & 108.7 & 1.04 \\
\hline & & $40 \times 40 \times 3$ & 2.10 & 0.0048 & 539.0 & 0.94 & 225 & 114.3 & 100.2 & 1.14 \\
\hline & & $50 \times 50 \times 3$ & 2.65 & 0.0033 & 483.0 & 0.83 & 286 & 114.6 & 108.7 & 1.05 \\
\hline & & $60 \times 60 \times 3$ & 3.17 & 0.0027 & 437.9 & 0.74 & 347 & 112.2 & 106.4 & 1.06 \\
\hline \multirow{11}{*}{$\begin{array}{l}\Xi \\
\Xi \\
\Xi \\
\Xi \\
\Xi \\
\Xi \\
\Xi \\
\Xi \\
\Xi\end{array}$} & \multirow{6}{*}{$\begin{array}{c}\mathrm{C} \\
1.4301\end{array}$} & $50 \times 25 \times 3$ & 0.91 & 0.0132 & 303.5 & 1.14 & 258 & 89.3 & 106.0 & 0.84 \\
\hline & & $80 \times 40 \times 3$ & 1.48 & 0.0044 & 271.4 & 1.08 & 431 & 126.8 & 134.2 & 0.94 \\
\hline & & $100 \times 50 \times 3$ & 1.88 & 0.0028 & 254.1 & 0.95 & 555 & 134.1 & 146.2 & 0.92 \\
\hline & & $100 \times 50 \times 3$ & 1.87 & 0.0028 & 254.1 & 0.95 & 555 & 134.3 & 140.4 & 0.96 \\
\hline & & $150 \times 50 \times 3$ & 1.88 & 0.0028 & 254.1 & 0.94 & 699 & 166.7 & 156.0 & 1.07 \\
\hline & & $50 \times 50 \times 3$ & 1.87 & 0.0028 & 254.1 & 0.98 & 404 & 100.7 & 125.0 & 0.81 \\
\hline & \multirow{5}{*}{$\begin{array}{c}\mathrm{C} \\
1.4318\end{array}$} & $50 \times 25 \times 3$ & 1.30 & 0.0126 & 582.5 & 1.14 & 267 & 178.2 & 186.2 & 0.96 \\
\hline & & $80 \times 40 \times 3$ & 1.88 & 0.0060 & 556.0 & 0.97 & 451 & 242.2 & 229.7 & 1.05 \\
\hline & & $100 \times 50 \times 3$ & 2.41 & 0.0039 & 509.4 & 0.87 & 571 & 252.3 & 233.8 & 1.08 \\
\hline & & $100 \times 50 \times 3$ & 2.44 & 0.0038 & 504.8 & 0.86 & 570 & 247.3 & 229.6 & 1.08 \\
\hline & & $150 \times 50 \times 3$ & 2.67 & 0.0034 & 486.4 & 0.81 & 721 & 285.7 & 228.2 & 1.25 \\
\hline \multirow{12}{*}{ 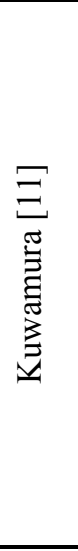 } & \multirow{8}{*}{$\begin{array}{l}\text { Lip. C } \\
1.4301\end{array}$} & $100 \times 50 \times 20 \times 3$ & 1.24 & 0.0065 & 278.0 & 1.20 & 641 & 213.1 & 211.4 & 1.01 \\
\hline & & $150 \times 50 \times 20 \times 3$ & 1.88 & 0.0028 & 250.6 & 0.97 & 791 & 193.2 & 197.0 & 0.98 \\
\hline & & $150 \times 65 \times 20 \times 3$ & 1.89 & 0.0028 & 250.6 & 0.96 & 873 & 211.1 & 214.8 & 0.98 \\
\hline & & $200 \times 75 \times 25 \times 3$ & 2.54 & 0.0017 & 216.5 & 0.84 & 1104 & 201.8 & 232.8 & 0.87 \\
\hline & & $35 \times 17 \times 7 \times 1$ & 1.29 & 0.0062 & 288.9 & 1.10 & 70 & 22.3 & 23.7 & 0.94 \\
\hline & & $50 \times 17 \times 7 \times 1$ & 1.97 & 0.0026 & 256.3 & 0.95 & 88 & 21.5 & 21.7 & 0.99 \\
\hline & & $50 \times 25 \times 7 \times 1$ & 1.97 & 0.0026 & 256.3 & 0.95 & 96 & 23.3 & 24.3 & 0.96 \\
\hline & & $70 \times 25 \times 8 \times 1$ & 2.71 & 0.0016 & 217.8 & 0.82 & 120 & 21.4 & 26.1 & 0.82 \\
\hline & \multirow{4}{*}{$\begin{array}{l}\text { Lip. C } \\
1.4318\end{array}$} & $100 \times 50 \times 20 \times 3$ & 1.75 & 0.0068 & 557.6 & 1.01 & 659 & 372.8 & 350.2 & 1.06 \\
\hline & & $150 \times 50 \times 20 \times 3$ & 2.67 & 0.0034 & 483.8 & 0.85 & 807 & 331.6 & 317.9 & 1.04 \\
\hline & & $150 \times 65 \times 20 \times 3$ & 2.67 & 0.0034 & 483.8 & 0.84 & 898 & 362.9 & 342.3 & 1.06 \\
\hline & & $200 \times 75 \times 25 \times 3$ & 3.58 & 0.0025 & 415.1 & 0.68 & 1139 & 319.5 & 377.8 & 0.85 \\
\hline \multirow{10}{*}{ 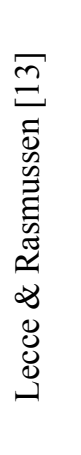 } & \multirow{4}{*}{$\begin{array}{l}\text { Lip. C } \\
1.4301\end{array}$} & $105 \times 90 \times 13 \times 2$ & 1.92 & 0.0025 & 229.2 & 0.95 & 565 & 123.3 & 116.0 & 1.06 \\
\hline & & $105 \times 90 \times 13 \times 2$ & 1.91 & 0.0025 & 229.2 & 0.95 & 565 & 123.5 & 116.0 & 1.06 \\
\hline & & $105 \times 90 \times 13 \times 2$ & 1.90 & 0.0025 & 229.2 & 0.96 & 565 & 123.7 & 116.0 & 1.07 \\
\hline & & $105 \times 90 \times 13 \times 2$ & 1.90 & 0.0025 & 229.2 & 0.96 & 565 & 123.7 & 116.0 & 1.07 \\
\hline & \multirow{4}{*}{$\begin{array}{l}\text { Lip. C } \\
1.4016\end{array}$} & $67 \times 57 \times 8 \times 1.13$ & 2.21 & 0.0021 & 243.6 & 0.90 & 211 & 46.2 & 50.0 & 0.92 \\
\hline & & $67 \times 57 \times 8 \times 1.13$ & 2.21 & 0.0021 & 243.6 & 0.90 & 211 & 46.2 & 50.0 & 0.92 \\
\hline & & $55 \times 55 \times 8 \times 1.13$ & 1.82 & 0.0030 & 264.9 & 0.97 & 188 & 48.3 & 51.0 & 0.95 \\
\hline & & $55 \times 55 \times 8 \times 1.13$ & 1.81 & 0.0030 & 264.9 & 0.97 & 188 & 48.4 & 51.0 & 0.95 \\
\hline & Lip. C & $105 \times 85 \times 15 \times 2$ & 2.10 & 0.0027 & 312.7 & 0.92 & 555 & 160.4 & 162.0 & 0.99 \\
\hline & 1.4003 & $105 \times 85 \times 15 \times 2$ & 2.10 & 0.0027 & 312.7 & 0.92 & 555 & 160.4 & 162.0 & 0.99 \\
\hline
\end{tabular}


Table 6 (contd.) Comparison of predicted results with tests.

\begin{tabular}{|c|c|c|c|c|c|c|c|c|c|c|}
\hline Ref. & $\begin{array}{l}\text { Type, } \\
\text { Grade }\end{array}$ & Nom. size & $\beta$ & $\varepsilon_{\mathrm{LB}}$ & $\begin{array}{c}\sigma_{\mathrm{LB}} \\
\mathrm{N} / \mathrm{mm}^{2}\end{array}$ & $\begin{array}{l}\text { Cor. } \\
\text { factor }\end{array}$ & $\begin{array}{c}\text { A } \\
\mathrm{mm}^{2} \\
\end{array}$ & $\begin{array}{c}\text { Pred } F_{u} \\
k N\end{array}$ & $\begin{array}{c}\text { Test } \mathrm{F}_{\mathrm{u}} \\
\mathrm{kN} \\
\end{array}$ & $\begin{array}{l}\text { Pred } F_{u} \\
/ \text { Test } F_{u}\end{array}$ \\
\hline \multirow{16}{*}{ 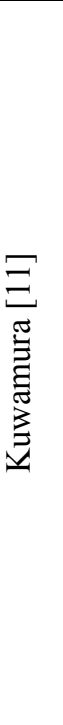 } & \multirow{8}{*}{$\begin{array}{c}\mathrm{H} \\
1.4301\end{array}$} & $50 \times 50$ & 0.93 & 0.0116 & 292.5 & 1.00 & 427 & 124.9 & 152.8 & 0.82 \\
\hline & & $50 \times 100$ & 1.85 & 0.0026 & 244.5 & 0.90 & 709 & 156.3 & 192.8 & 0.81 \\
\hline & & $100 \times 50$ & 1.17 & 0.0068 & 277.0 & 1.00 & 571 & 158.2 & 171.1 & 0.92 \\
\hline & & $100 \times 75$ & 1.40 & 0.0046 & 266.6 & 1.00 & 722 & 192.5 & 199.9 & 0.96 \\
\hline & & $100 \times 100$ & 1.86 & 0.0026 & 244.5 & 0.90 & 863 & 189.6 & 203.4 & 0.93 \\
\hline & & $150 \times 100$ & 1.86 & 0.0026 & 244.5 & 0.90 & 1012 & 222.4 & 207.7 & 1.07 \\
\hline & & $200 \times 100$ & 2.39 & 0.0017 & 215.3 & 0.82 & 1157 & 203.7 & 206.1 & 0.99 \\
\hline & & $200 \times 150$ & 2.80 & 0.0014 & 199.0 & 0.75 & 1460 & 219.3 & 231.4 & 0.95 \\
\hline & \multirow{8}{*}{$\begin{array}{c}\mathrm{H} \\
1.4318\end{array}$} & $50 \times 50$ & 1.30 & 0.0116 & 579.8 & 1.00 & 435 & 252.4 & 253.4 & 1.00 \\
\hline & & $50 \times 100$ & 2.67 & 0.0031 & 472.6 & 0.77 & 730 & 267.2 & 289.7 & 0.92 \\
\hline & & $100 \times 50$ & 1.67 & 0.0070 & 563.0 & 0.93 & 591 & 309.2 & 279.5 & 1.11 \\
\hline & & $100 \times 75$ & 1.99 & 0.0050 & 543.0 & 0.88 & 739 & 352.7 & 309.9 & 1.14 \\
\hline & & $100 \times 100$ & 2.65 & 0.0032 & 477.2 & 0.78 & 888 & 329.7 & 323.4 & 1.02 \\
\hline & & $150 \times 100$ & 2.64 & 0.0032 & 477.2 & 0.78 & 1041 & 387.2 & 310.1 & 1.25 \\
\hline & & $200 \times 100$ & 3.42 & 0.0024 & 406.2 & 0.66 & 1094 & 292.9 & 311.5 & 0.94 \\
\hline & & $200 \times 150$ & 3.99 & 0.0022 & 385.6 & 0.57 & 1491 & 328.7 & 359.7 & 0.91 \\
\hline \multirow{4}{*}{ 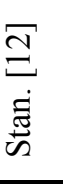 } & \multirow{4}{*}{$\begin{array}{c}\mathrm{H} \\
1.4301 \\
1.4462\end{array}$} & $160 \times 80$ & 0.90 & 0.0146 & 348.8 & 1.00 & 2430 & 847.7 & 885.0 & 0.96 \\
\hline & & $160 \times 160$ & 0.92 & 0.0137 & 346.1 & 1.00 & 4074 & 1410.1 & 1440.0 & 0.98 \\
\hline & & $320 \times 160$ & 1.94 & 0.0028 & 382.0 & 0.89 & 4570 & 1549.1 & 1430.0 & 1.08 \\
\hline & & $160 \times 160$ & 1.19 & 0.0132 & 569.0 & 1.00 & 4094 & 2329.7 & 2590.0 & 0.90 \\
\hline$\Xi$ & $\begin{array}{c}\text { SHS } \\
1.4301\end{array}$ & $60 \times 60 \times 5$ & 0.57 & 0.0720 & 749.2 & 1.03 & 999 & 770.9 & 801.0 & 0.96 \\
\hline \multirow{2}{*}{ 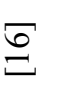 } & \multirow{2}{*}{$\begin{array}{c}\text { SHS } \\
1.4306\end{array}$} & $80 \times 80 \times 3$ & 1.187 & 0.0108 & 511.0 & 1.02 & 908 & 473.2 & 485.0 & 0.98 \\
\hline & & $80 \times 80 \times 3$ & 1.176 & 0.0110 & 512.3 & 1.02 & 900 & 470.3 & 471.0 & 1.00 \\
\hline \multirow{12}{*}{ 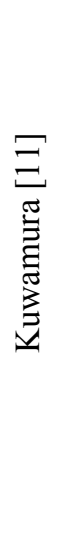 } & \multirow{6}{*}{$\begin{array}{c}\text { SHS } \\
1.4301\end{array}$} & $50 \times 50 \times 3$ & 0.61 & 0.0348 & 353.3 & 1.18 & 515 & 215.5 & 241.0 & 0.89 \\
\hline & & $75 \times 75 \times 3$ & 0.92 & 0.0128 & 305.8 & 1.10 & 814 & 274.9 & 282.4 & 0.97 \\
\hline & & $100 \times 100 \times 3$ & 1.24 & 0.0065 & 285.2 & 1.08 & 1104 & 339.5 & 323.2 & 1.05 \\
\hline & & $125 \times 125 \times 3$ & 1.58 & 0.0039 & 270.9 & 1.00 & 1400 & 379.2 & 353.8 & 1.07 \\
\hline & & $150 \times 150 \times 3$ & 1.90 & 0.0027 & 254.4 & 0.94 & 1686 & 403.1 & 363.9 & 1.11 \\
\hline & & $200 \times 200 \times 3$ & 2.53 & 0.0017 & 220.8 & 0.83 & 2265 & 413.3 & 364.8 & 1.13 \\
\hline & \multirow{6}{*}{$\begin{array}{c}\text { SHS } \\
1.4318\end{array}$} & $50 \times 50 \times 3$ & 0.86 & 0.0320 & 622.5 & 1.15 & 542 & 388.3 & 377.5 & 1.03 \\
\hline & & $75 \times 75 \times 3$ & 1.30 & 0.0125 & 592.8 & 1.09 & 855 & 553.2 & 459.4 & 1.20 \\
\hline & & $100 \times 100 \times 3$ & 1.77 & 0.0067 & 570.9 & 0.98 & 1132 & 632.6 & 468.7 & 1.35 \\
\hline & & $125 \times 125 \times 3$ & 2.23 & 0.0044 & 534.0 & 0.89 & 1451 & 687.1 & 480.5 & 1.43 \\
\hline & & $150 \times 150 \times 3$ & 2.68 & 0.0033 & 487.7 & 0.81 & 1760 & 694.0 & 483.0 & 1.44 \\
\hline & & $200 \times 200 \times 3$ & 3.58 & 0.0025 & 419.5 & 0.66 & 2346 & 646.4 & 511.9 & 1.26 \\
\hline
\end{tabular}


Table 6 (contd.) Comparison of predicted results with tests.

\begin{tabular}{|c|c|c|c|c|c|c|c|c|c|c|}
\hline Ref. & $\begin{array}{l}\text { Type, } \\
\text { Grade }\end{array}$ & Nom. size & $\beta$ & $\varepsilon_{\mathrm{LB}}$ & $\begin{array}{c}\sigma_{\mathrm{LB}} \\
\mathrm{N} / \mathrm{mm}^{2} \\
\end{array}$ & $\begin{array}{l}\text { Cor. } \\
\text { factor }\end{array}$ & $\begin{array}{c}\mathrm{A} \\
\mathrm{mm}^{2} \\
\end{array}$ & $\begin{array}{c}\text { Pred } \mathrm{F}_{\mathrm{u}} \\
\mathrm{kN}\end{array}$ & $\begin{array}{c}\text { Test } \mathrm{F}_{\mathrm{u}} \\
\mathrm{kN}\end{array}$ & $\begin{array}{l}\text { Pred } F_{u} \\
/ \text { Test } F_{u}\end{array}$ \\
\hline \multirow{15}{*}{ 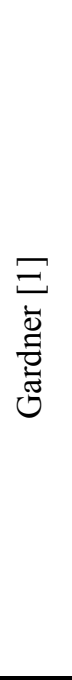 } & \multirow{15}{*}{$\begin{array}{c}\text { SHS } \\
1.4301\end{array}$} & $80 \times 80 \times 4$ & 1.02 & 0.0175 & 600.3 & 1.04 & 1080 & 676.9 & 727.0 & 0.93 \\
\hline & & $80 \times 80 \times 4$ & 0.99 & 0.0190 & 607.4 & 1.04 & 1124 & 712.1 & 714.0 & 1.00 \\
\hline & & $80 \times 80 \times 4$ & 0.99 & 0.0191 & 607.9 & 1.04 & 1125 & 713.4 & 711.0 & 1.00 \\
\hline & & $80 \times 80 \times 4$ & 0.71 & 0.0212 & 355.5 & 1.00 & 1105 & 392.9 & 309.0 & 1.27 \\
\hline & & $80 \times 80 \times 4$ & 0.73 & 0.0198 & 352.3 & 1.00 & 1080 & 380.5 & 335.0 & 1.14 \\
\hline & & $100 \times 100 \times 2$ & 2.18 & 0.0027 & 318.1 & 0.86 & 743 & 203.5 & 197.0 & 1.03 \\
\hline & & $100 \times 100 \times 2$ & 2.17 & 0.0028 & 323.7 & 0.86 & 739 & 206.2 & 187.0 & 1.10 \\
\hline & & $100 \times 100 \times 3$ & 1.44 & 0.0061 & 427.7 & 1.02 & 1101 & 478.1 & 489.0 & 0.98 \\
\hline & & $100 \times 100 \times 3$ & 1.46 & 0.0060 & 426.5 & 1.02 & 1089 & 471.5 & 496.0 & 0.95 \\
\hline & & $100 \times 100 \times 4$ & 1.16 & 0.0116 & 542.6 & 1.03 & 1431 & 803.4 & 779.0 & 1.03 \\
\hline & & $100 \times 100 \times 4$ & 1.16 & 0.0116 & 542.6 & 1.03 & 1426 & 800.6 & 774.0 & 1.03 \\
\hline & & $100 \times 100 \times 6$ & 0.77 & 0.0329 & 679.5 & 1.05 & 2147 & 1530.0 & 1513.0 & 1.01 \\
\hline & & $100 \times 100 \times 6$ & 0.78 & 0.0325 & 678.4 & 1.05 & 2153 & 1531.3 & 1507.0 & 1.02 \\
\hline & & $100 \times 100 \times 8$ & 0.46 & 0.0779 & 542.7 & 1.07 & 2785 & 1615.5 & 1630.0 & 0.99 \\
\hline & & $100 \times 100 \times 8$ & 0.46 & 0.0783 & 543.2 & 1.07 & 2781 & 1614.8 & 1797.0 & 0.90 \\
\hline \multirow{2}{*}{$\Xi$} & \multirow{2}{*}{$\begin{array}{c}\text { RHS } \\
1.4301\end{array}$} & $150 \times 100 \times 3$ & 1.98 & 0.0027 & 274.2 & 0.9 & 1397 & 344.7 & 372.0 & 0.93 \\
\hline & & $150 \times 100 \times 6$ & 1.03 & 0.0119 & 433.1 & 1.04 & 2683 & 1208.5 & 1292.0 & 0.94 \\
\hline \multirow{16}{*}{ 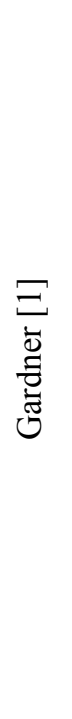 } & \multirow{16}{*}{$\begin{array}{l}\text { RHS } \\
1.4301\end{array}$} & $60 \times 40 \times 4$ & 0.72 & 0.0395 & 692.6 & 1.05 & 675 & 493.2 & 492.0 & 1.00 \\
\hline & & $60 \times 40 \times 4$ & 0.72 & 0.0393 & 692.0 & 1.05 & 675 & 492.7 & 497.0 & 0.99 \\
\hline & & $120 \times 80 \times 3$ & 1.86 & 0.0044 & 436.5 & 0.93 & 1109 & 449.1 & 452.0 & 0.99 \\
\hline & & $120 \times 80 \times 3$ & 1.88 & 0.0043 & 433.0 & 0.93 & 1100 & 441.0 & 447.0 & 0.99 \\
\hline & & $120 \times 80 \times 6$ & 0.96 & 0.0201 & 624.2 & 1.06 & 2107 & 1388.0 & 1459.0 & 0.95 \\
\hline & & $120 \times 80 \times 6$ & 0.96 & 0.0201 & 624.2 & 1.06 & 2108 & 1388.6 & 1465.0 & 0.95 \\
\hline & & $150 \times 100 \times 4$ & 1.53 & 0.0048 & 346.2 & 0.98 & 1799 & 611.3 & 660.0 & 0.93 \\
\hline & & $150 \times 100 \times 4$ & 1.52 & 0.0048 & 346.2 & 0.98 & 1805 & 613.7 & 659.0 & 0.93 \\
\hline & & $100 \times 50 \times 2$ & 2.24 & 0.0026 & 312.4 & 0.86 & 529 & 142.0 & 182.0 & 0.78 \\
\hline & & $100 \times 50 \times 2$ & 2.26 & 0.0026 & 312.4 & 0.86 & 529 & 141.7 & 181.0 & 0.78 \\
\hline & & $100 \times 50 \times 3$ & 1.60 & 0.0061 & 506.0 & 0.97 & 811 & 398.1 & 407.0 & 0.98 \\
\hline & & $100 \times 50 \times 3$ & 1.60 & 0.0061 & 506.0 & 0.97 & 811 & 398.1 & 415.0 & 0.96 \\
\hline & & $100 \times 50 \times 4$ & 1.19 & 0.0109 & 540.1 & 1.04 & 1026 & 576.3 & 626.0 & 0.92 \\
\hline & & $100 \times 50 \times 4$ & 1.21 & 0.0105 & 537.3 & 1.04 & 1014 & 566.5 & 627.0 & 0.90 \\
\hline & & $100 \times 50 \times 6$ & 0.77 & 0.0330 & 711.5 & 1.07 & 1558 & 1181.5 & 1217.0 & 0.97 \\
\hline & & $100 \times 50 \times 6$ & 0.77 & 0.0332 & 712.1 & 1.07 & 1559 & 1182.4 & 1217.0 & 0.97 \\
\hline
\end{tabular}

Table 7 Summary of the comparison between the proposed method and test results.

\begin{tabular}{cc|cc|cc|cc|cc|cc}
\hline \multicolumn{2}{c|}{ Angle } & \multicolumn{2}{c|}{ Channel } & \multicolumn{2}{c|}{ Lip. channel } & \multicolumn{2}{c|}{ H section } & \multicolumn{2}{c|}{ SHS } & \multicolumn{2}{c}{ RHS } \\
\hline avg. & s. dev. & avg. & s. dev. & avg. & s. dev. & avg. & s. dev. & avg. & s. dev. & avg. & s. dev. \\
\hline 1.00 & 0.11 & 1.00 & 0.13 & 0.98 & 0.07 & 0.98 & 0.11 & 1.07 & 0.15 & 0.94 & 0.06 \\
\hline
\end{tabular}

Table 7 (contd.) Summary of the comparison between the proposed method and test results.

\begin{tabular}{cc|cc|cc}
\hline \multicolumn{2}{c|}{ Open sections } & \multicolumn{2}{c|}{ Hollow sections } & \multicolumn{2}{c}{ All Sections } \\
\hline avg. & s. dev. & avg. & s. dev. & avg. & s. dev. \\
\hline 0.99 & 0.10 & 1.02 & 0.14 & 1.00 & 0.12 \\
\hline
\end{tabular}


Table 8 Comparison between FE predictions and test results for the SHS Grade 1.4318 tested by Kuwamura [11]

\begin{tabular}{|c|c|c|c|c|c|}
\hline Nominal size & $\begin{array}{c}\text { Test } \mathrm{F}_{\mathrm{u}} \\
\mathrm{kN}\end{array}$ & $\begin{array}{c}\mathrm{FE} \mathrm{F}_{\mathrm{u}} \\
\mathrm{kN}\end{array}$ & $\begin{array}{c}\text { Pred Fu } \\
\mathrm{kN} \\
\end{array}$ & $\begin{array}{l}\text { Pred } F_{u} \\
/ \text { Test } F_{u} \\
\end{array}$ & $\begin{array}{l}\operatorname{Pred~Fu}_{\mathrm{u}} \\
/ \mathrm{FE} \mathrm{F}_{\mathrm{u}}\end{array}$ \\
\hline $50 \times 50 \times 3$ & 377 & 407 & 388 & 1.03 & 0.95 \\
\hline $75 \times 75 \times 3$ & 459 & 549 & 553 & 1.20 & 1.01 \\
\hline $100 \times 100 \times 3$ & 469 & 580 & 633 & 1.35 & 1.09 \\
\hline $125 \times 125 \times 3$ & 480 & 574 & 687 & 1.43 & 1.20 \\
\hline $150 \times 150 \times 3$ & 483 & 592 & 694 & 1.44 & 1.17 \\
\hline $200 \times 200 \times 3$ & 512 & 655 & 646 & 1.26 & 0.99 \\
\hline \multirow{2}{*}{\multicolumn{4}{|c|}{$\begin{array}{r}\text { Average } \\
\text { Standard Deviation }\end{array}$}} & 1.29 & 1.07 \\
\hline & & & & 0.16 & 0.10 \\
\hline
\end{tabular}



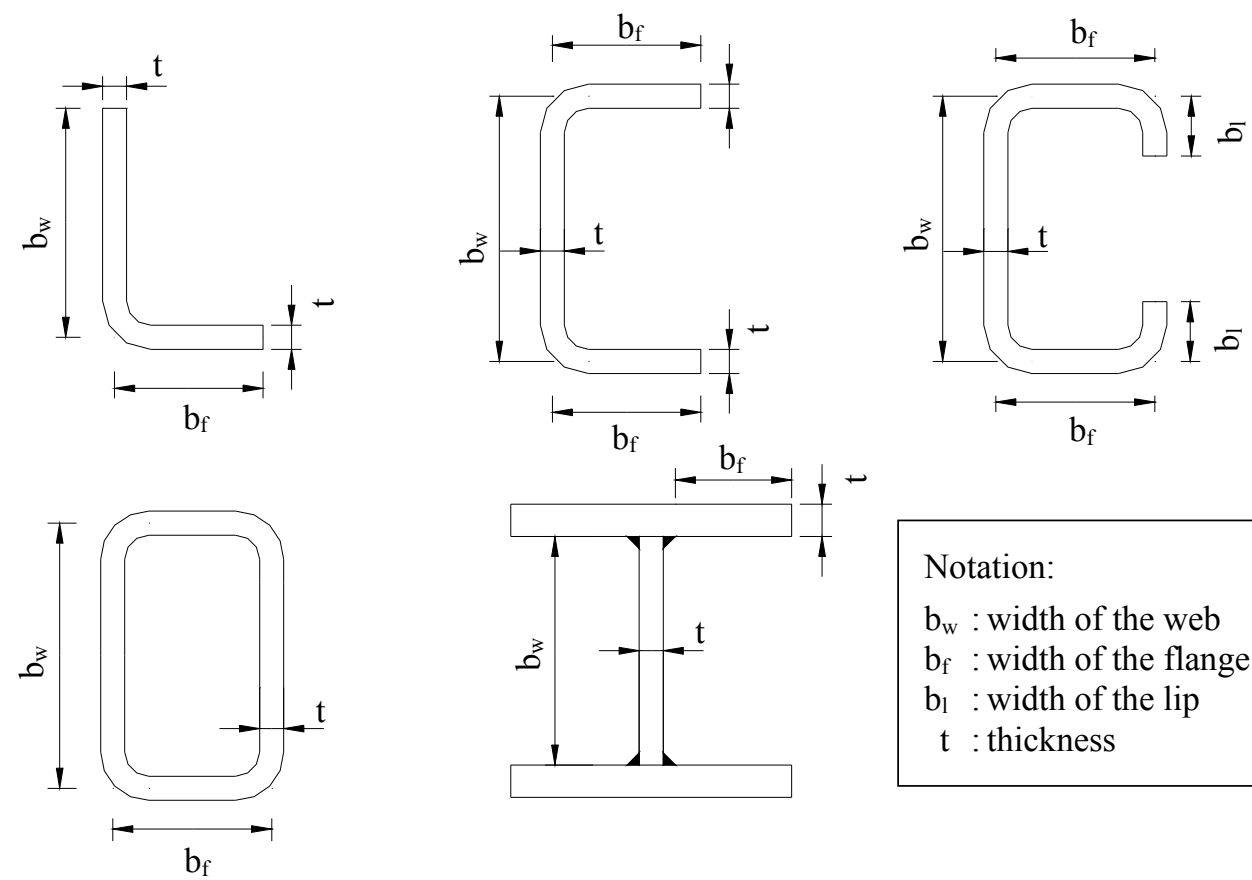

\section{Notation:}

$b_{w}:$ width of the web

$b_{f}:$ width of the flange

$b_{1}:$ width of the lip

$\mathrm{t}$ : thickness

Figure 1 Dimension of compression elements used in the present study.

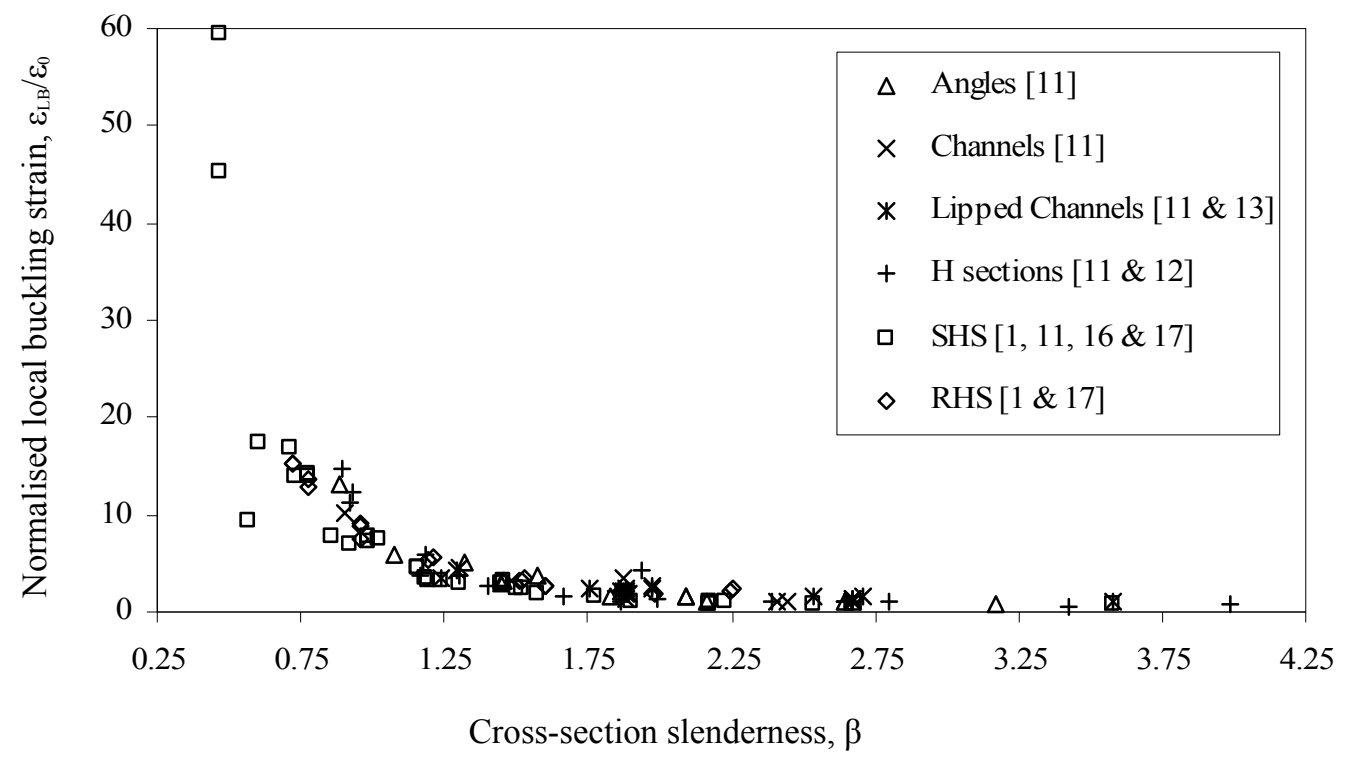

Figure 2 Cross-section deformation capacity versus cross-section slenderness for all sections. 


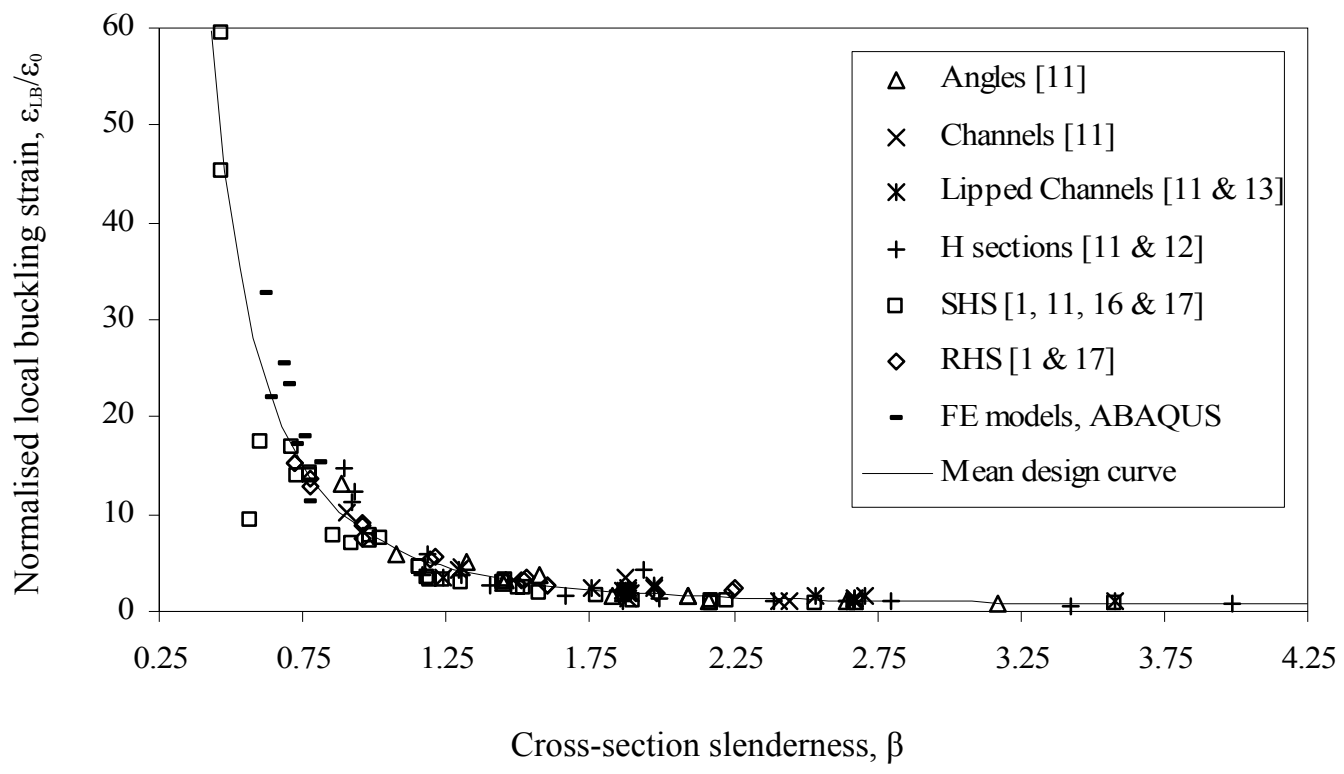

Figure 3 Mean design curve to determine cross-section deformation capacity.

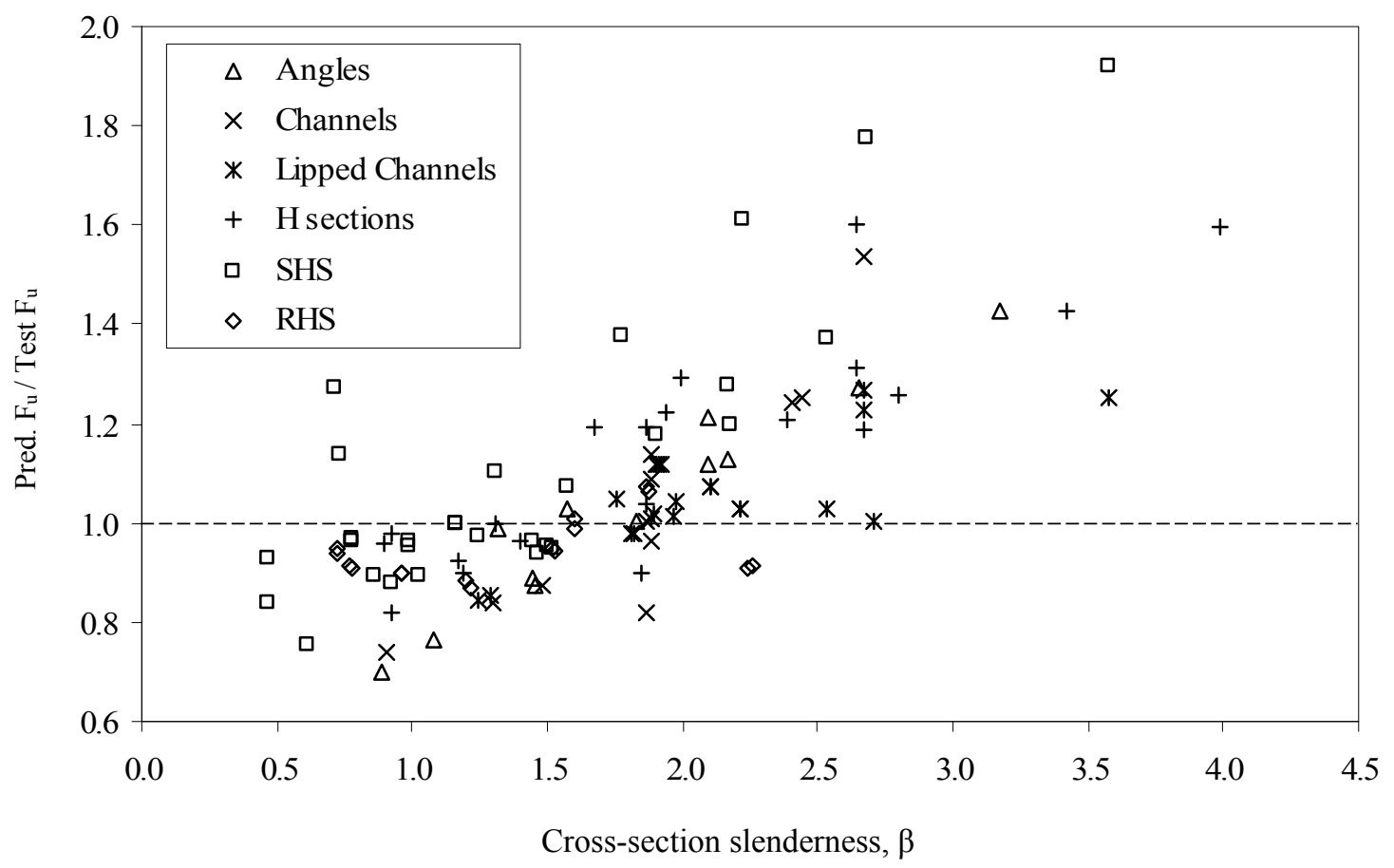

Figure 4 Comparison between predicted compressive strengths to the test results. 


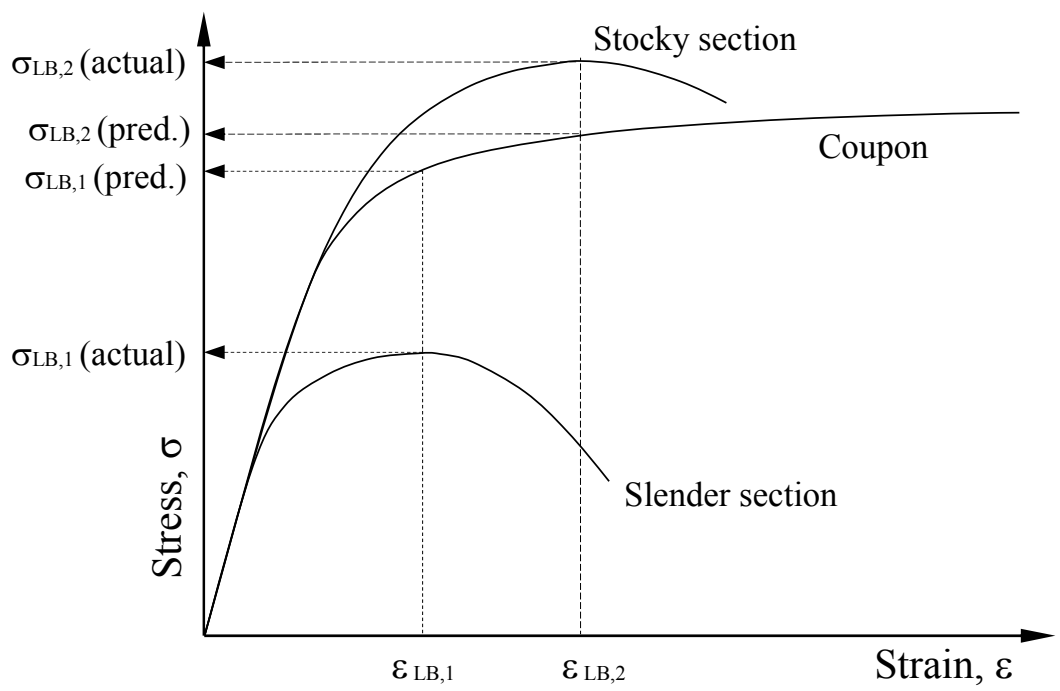

Figure 5 Behaviour of slender and stocky stub columns showing differences with coupon.

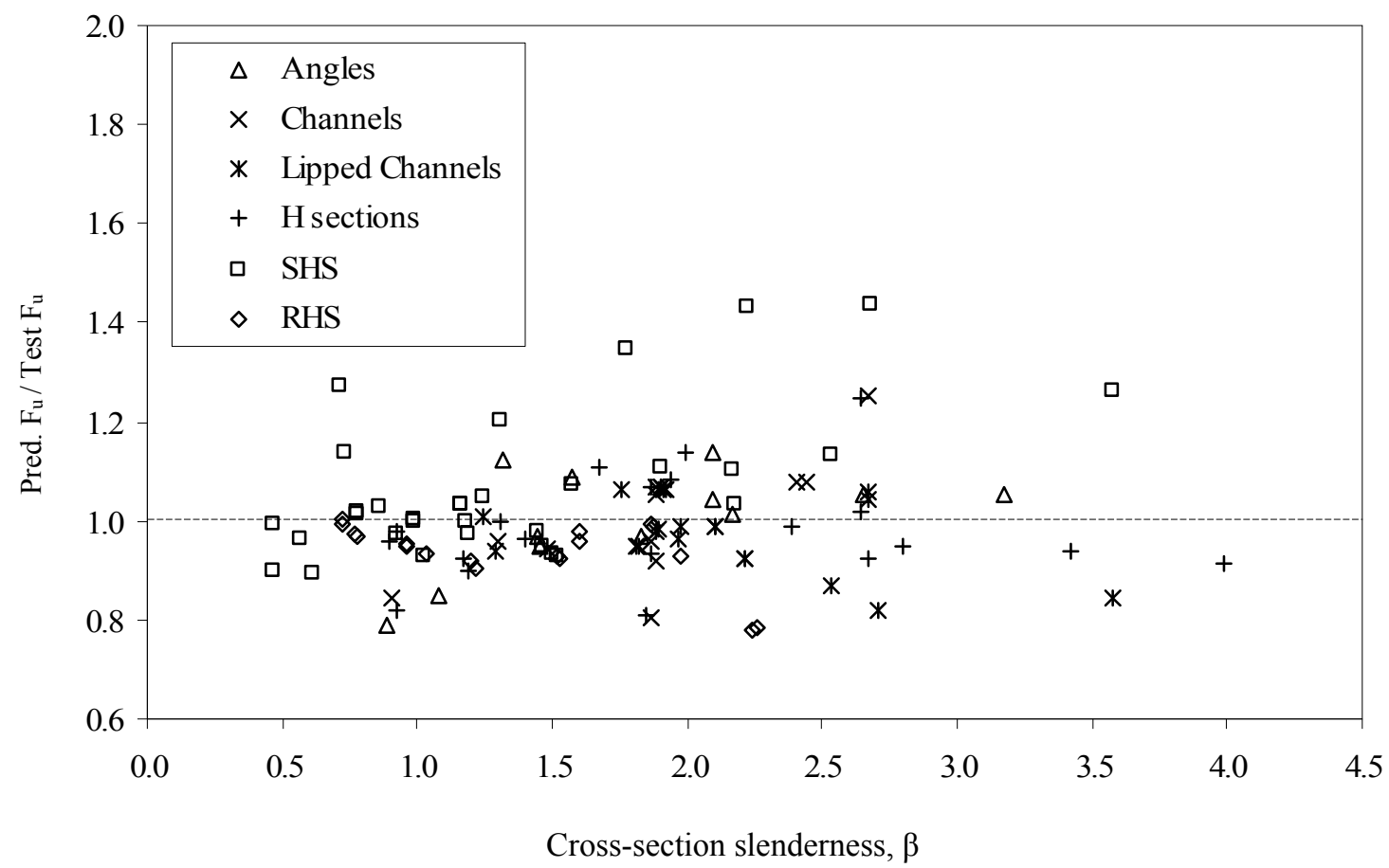

Figure 6 Comparison between corrected predictions and test results. 